\title{
DLGS97/SAP97 Is Developmentally Upregulated and Is Required for Complex Adult Behaviors and Synapse Morphology and Function
}

\author{
Carolina Mendoza-Topaz, ${ }^{1}$ Francisco Urra, ${ }^{1}$ Romina Barría, ${ }^{1}$ Valeria Albornoz, ${ }^{1}$ Diego Ugalde, ${ }^{1}$ Ulrich Thomas, ${ }^{2}$ \\ Eckart D. Gundelfinger, ${ }^{2}$ Ricardo Delgado, ${ }^{4}$ Manuel Kukuljan, ${ }^{1}$ Parthena D. Sanxaridis, ${ }^{3}$ Susan Tsunoda, ${ }^{3}$ \\ M. Fernanda Ceriani, ${ }^{5}$ Vivian Budnik, ${ }^{6}$ and Jimena Sierralta ${ }^{1}$ \\ ${ }^{1}$ Institute of Biomedical Sciences, Universidad de Chile and Centro de Neurociencias Integradas, Santiago, Chile, ${ }^{2}$ Leibniz Institute for Neurobiology, D- \\ 39118 Magdeburg, Germany, ${ }^{3}$ Department of Biology, Boston University, Boston, Massachusetts 02215, ${ }^{4}$ Millenium Institute for Cell Dynamics and \\ Biotechnology, Santiago, Chile, ${ }^{5}$ Fundación Instituto Leloir, 1405 Buenos Aires, Argentina, and ${ }^{6}$ Department of Neurobiology, University of Massachusetts \\ Medical School, Worcester, Massachusetts 01605
}

\begin{abstract}
The synaptic membrane-associated guanylate kinase (MAGUK) scaffolding protein family is thought to play key roles in synapse assembly and synaptic plasticity. Evidence supporting these roles in vivo is scarce, as a consequence of gene redundancy in mammals. The genome of Drosophila contains only one MAGUK gene, discs large (dlg), from which two major proteins originate: DLGA [PSD95 (postsynaptic density 95)-like] and DLGS97 [SAP97 (synapse-associated protein)-like]. These differ only by the inclusion in DLGS97 of an L27 domain, important for the formation of supramolecular assemblies. Known $\mathrm{dlg}$ mutations affect both forms and are lethal at larval stages attributable to tumoral overgrowth of epithelia. We generated independent null mutations for each, $d \lg A$ and $d l g S 97$. These allowed unveiling of a shift in expression during the development of the nervous system: predominant expression of DLGA in the embryo, balanced expression of both during larval stages, and almost exclusive DLGS97 expression in the adult brain. Loss of embryonic DLGS97 does not alter the development of the nervous system. At larval stages, DLGA and DLGS97 fulfill both unique and partially redundant functions in the neuromuscular junction. Contrary to $d l g$ and $d \lg A$ mutants, $d l g S 97$ mutants are viable to adulthood, but they exhibit marked alterations in complex behaviors such as phototaxis, circadian activity, and courtship, whereas simpler behaviors like locomotion and odor and light perception are spared. We propose that the increased repertoire of associations of a synaptic scaffold protein given by an additional domain of protein-protein interaction underlies its ability to integrate molecular networks required for complex functions in adult synapses.
\end{abstract}

Key words: scaffold proteins; synapses; Drosophila; DLG; behavior; MAGUK; SAP97

\section{Introduction}

Synaptic transmission relies on the proper spatial organization of protein complexes, which are shaped by scaffolding proteins bearing multiple protein interaction domains. The membraneassociated guanylate kinase (MAGUK) family of scaffolding proteins and in particular the synapse-associated protein (SAP) subfamily, is extensively expressed in the brain and links synaptic

\footnotetext{
Received May 31, 2007; revised Nov. 22, 2007; accepted Nov. 22, 2007.

This work was supported by the Max Planck Award for international collaborations from the Alexander von Humboldt Society and the Max Planck Society (E.G.) and Grants FONDECYT 1030795, ICMP04-068-F, and ACT-47 (J.S., M.K.), and National Institutes of Health Grants FIC R03 TW007068 (J.S., V.B.) and R01 NS042629 (V.B.). We thank Dr. Michael Gorczyca for helpful comments on this manuscript. We also thank Ms. Rebeca Baeza for technical assistance, Mr. Norberto Gherbessi for assistance with electron microscopy, and the Electron Microscopy Facility at University of Massachusetts Medical School supported by the Diabetes Endocrinology Research Center Grant DK32520. We thank the Bloomington Stock Center for providing fly stocks and Dr. A. DiAntonio for anti-GluRIII antibodies

Correspondence should be addressed to Dr. Jimena Sierralta, Program of Physiology and Biophysics, Institute for Biomedical Sciences, Faculty of Medicine, Universidad de Chile, Independencia 1027, P.0. Box 70005, Santiago, Chile.E-mail: jimena@neuro.med.uchile.cl.

DOI:10.1523/JNEUROSCI.4395-07.2008

Copyright $\odot 2008$ Society for Neuroscience $\quad 0270-6474 / 08 / 280304-11 \$ 15.00 / 0$
}

proteins to signal transduction cascades, the cytoskeleton, and the endocytic machinery (Fanning and Anderson, 1999; Garner et al., 2000a,b; Sheng and Lee, 2001; Tepass et al., 2001).

In vertebrates, SAPs postsynaptic density 95 (PSD95)/SAP90, SAP102/neuroendocrine-Discs large (NEDLG), SAP97/human DLG (hDLG), and PSD93/Chapsyn-110 are thought to play key roles in synapse assembly and plasticity (Rumbaugh et al., 2003; Funke et al., 2005; Regalado et al., 2006); in vivo evidence for these roles has been scarce, likely because of functional redundancy. Although studies in cultured neurons demonstrate a role for SAPs in protein clustering and dendritic spine formation, PSD95 (Migaud et al., 1998) or PSD93 (McGee et al., 2001) knock-out mice lack obvious alterations in synaptic structure and function. Nevertheless, behavioral analysis of these mutants reveals learning and memory defects. SAP97 mutant mice are not viable because of profound developmental defects. However, the synaptic function of cultured SAP97 mutant neurons is normal (Caruana and Bernstein, 2001; Klocker et al., 2002).

Drosophila contains a single SAP gene, $d l g$, with functions in epithelial development (Woods et al., 1996), asymmetric cell di- 
vision (Ohshiro et al., 2000), and the development and function of the larval neuromuscular junction (NMJ) (Lahey et al., 1994; Budnik et al., 1996; Tejedor et al., 1997; Thomas et al., 1997). In $d l g$ mutants, all gene products are severely decreased, which leads to early pupal lethality and thus precludes their analysis beyond this stage.

The $d l g$ locus generates multiple products through different transcription start sites and mRNA splicing (Mendoza et al., 2003). The two main products are $d \lg A$ (PSD95-like) and $d l g S 97$ (SAP97-like) transcripts. Unlike DLGA, DLGS97 contains an extended N-terminal region bearing an L27 domain. L27 domains form tetrameric complexes with other L27 domain-containing proteins, providing a platform for supramolecular assemblies (Doerks et al., 2000; Feng et al., 2004; Petrosky et al., 2005). Although DLGA is broadly expressed in epithelia, somatic muscles, and nervous system (Woods and Bryant, 1991), DLGS97 is exclusive to the nervous system and the NMJ (Mendoza et al., 2003).

To investigate the function of DLGA and DLGS97 in vivo, we generated form-specific mutations. We found that during nervous system development there is a shift in $d l g$ variant usage: DLGA during embryonic development, coexistence of DLGA and DLGS97 in the larvae, and predominant DLGS97 expression in the adult. Contrary to $d l g A$ mutants, $d l g S 97$ flies are viable, but complex behaviors, such as phototaxis, circadian rhythms, and courtship are disrupted. At the larval NMJ, isoform-specific mutations resulted in functional and structural abnormalities, but some phenotypes observed in $d l g$ mutants were not detected, suggesting reciprocal compensation. These results highlight specific functions of two closely related SAPs that may arise from the ability of DLGS97 to form supramolecular complexes through its L27 domain.

\section{Materials and Methods}

Fly strains and genetics

The following strains were used: the UAS strains UAS-dlgA-EGFP and $U A S-E G F P$-dlgS97, the pan-neuronal Gal4 activator strain elav-Gal4 (Bloomington Stock Center, Bloomington, IN), the P-element insertion lines NP7225 (referred as dlgS97 $7^{N P 7225}$ here; National Institute of Genetics, Shizuoka, Japan) and EY5003 (Bloomington Stock Center), the transposase-bearing strain $\Delta 2-3 \mathrm{Dr} / \mathrm{TM} 2$ (provided by A. García Bellido, Universidad Autónoma de Madrid, Spain), and the phototransduction mutant inaD (Pak, 1979). All crosses were performed at $25^{\circ} \mathrm{C}$, but once the progeny of UAS/Gal4 crosses reached the wandering third instar larval stage they were shifted to $29^{\circ} \mathrm{C}$ to maximize expression of transgenes for studies in adult stages.

Transposition. Because $d l g$ is necessary for spermatogenesis (U. Thomas, unpublished observations), a gene region with a duplication of the $d l g$ locus in the $\mathrm{Y}$ chromosome, $\mathrm{Dp}(1 ; 2) \mathrm{v}^{+} 75 \mathrm{~d}$ (Bloomington Stock Center) was incorporated to the $\Delta 2-3 \mathrm{Dr} / \mathrm{TM} 2$ strain and males were crossed with $\operatorname{dlgS} 97^{N P 7225}$ females or $d \lg A^{E Y 5003}$ to mobilize the P-element. A total of 320 excision lines was generated and analyzed for DLGS97 expression in Western blots, 10 lethal lines with tumorous larvae were also analyzed for no complementation with $\mathrm{dlg}^{m 52}$ and for expression of DLG. For rescue experiments, the dlgS97 mutant was recombined with the elav-Gal4 insertion.

\section{Immunohistochemistry}

Embryos and body wall muscle preparations were stained as described previously (Thomas et al., 1997; Mendoza et al., 2003). Primary antibodies used were rabbit polyclonal anti-DLG ${ }_{\mathrm{S} 97 \mathrm{~N}}(1: 500-1: 2000)$ (Mendoza et al., 2003), rat anti-Scribble (Scrib) (1:1000) (Y. F. Fuentes-Medel, S. Marfatia, and V. Budnik, unpublished observation), rabbit antiglutamate receptor III (GluRIII) (1:200) (Marrus et al., 2004), and Cy-5conjugated anti-HRP (1:200; Jackson ImmunoResearch, West Grove, $\mathrm{PA})$. The following mouse monoclonal antibodies used were from De- velopmental Studies Hybridoma Bank (University of Iowa, Iowa City, IA): anti-Fasciclin II (FasII) (1D4; 1:2) and anti-DLG ${ }_{\mathrm{PDZ}}(4 \mathrm{~F} 3 ; 1: 500)$. HRP- or fluorescent-coupled secondary antibodies were from Jackson ImmunoResearch or Invitrogen (Eugene, OR). After immunocytochemical procedures, samples were mounted in $70 \%$ glycerol in PBS or Vectashield mounting medium (Vector Laboratories, Burlingame, CA). Images were captured using a digital camera (Nikon Coolpix E500; Nikon, Tokyo, Japan) coupled to a Nikon E400 microscope, or a confocal microscope (LSM 510 Pascal; Carl Zeiss MicroImaging, Oberkochen, Germany). Quantification of confocal images was performed using Volocity 4.0 imaging software (Improvision, Lexington, MA) measuring the density of the fluorescence and normalizing by the average density of the control.

\section{Western blots}

Embryos were homogenized in homogenization buffer $(50 \mathrm{~mm}$ Tris-Cl, $\mathrm{pH} 7.5,150 \mathrm{~mm} \mathrm{NaCl}$ ) and centrifuged for $10 \mathrm{~min}$ at $800 \times \mathrm{g}$, and the pellet was resuspended in RIPA buffer $(0.15 \mathrm{M} \mathrm{NaCl}, 1 \% \mathrm{NP}-40,0.5 \%$ sodium deoxycholate, $0.1 \%$ SDS, 1 mм EDTA, and $0.2 \mathrm{M}$ Tris-Cl, $\mathrm{pH} 7.5$ ) supplemented with a protease inhibitor mixture (Boehringer, Mannheim, Germany). Larval brains were dissected in cold calcium-free dissection buffer and homogenized in RIPA buffer supplemented with protease inhibitor mixture. Adult heads were homogenized directly in RIPA buffer. Proteins were separated in 10\% acrylamide SDS-PAGE, transferred to nitrocellulose membranes, and incubated with rabbit anti$D_{\text {DLG }}$ S97N (1:3000) (Mendoza et al., 2003), mouse anti-DLG ${ }_{\mathrm{PDZ}}$ (4F3; 1:1500), or mouse anti $\beta$-tubulin (12G10; 1:1000; Developmental Studies Hybridoma Bank, University of Iowa, Iowa City, IA) antibodies. Quantification of signal intensity in Western blots was performed using Quantity One software (Bio-Rad, Hercules, CA).

\section{Genomic PCR}

PCR was performed on genomic DNA obtained from single flies homogenized in DNA buffer (10 mm Tris-Cl, pH 8.2, 1 mm EDTA, $25 \mathrm{~mm} \mathrm{NaCl}$ ) with $200 \mathrm{mg} / \mathrm{ml}$ freshly added proteinase K. Primers used for genomic PCR to map P-element excision-derived deletions were as follows: for $d \lg S 97^{138}, 5^{\prime}$-GCAAACCAAAGGCAAAATAA and $5^{\prime}$-ATCGCTCTCGGA CTTCTCAA; for $d l g S 97^{5}, 5^{\prime}$-CGCTTGGTAGGGCAGTAGAG and 5'-GGTCTCCG CTGTCTTTTGTT; and for $d l g A^{40-2}, 5^{\prime}$ ATATACATACATTTTGCGCTTCT and 5'-CCACAAGCACACTGAAAATG.

\section{Electron microscopy and bouton morphometry}

Body wall muscles were prepared for transmission electron microscopy, and boutons were serially sectioned and subjected to morphological analysis as described by Lahey et al. (1994). Briefly, electron micrographs taken at $11,500 \times$ magnification were used to identify bouton midlines (section of largest diameter within a serially sectioned bouton) where the perimeter of subsynaptic reticulum (SSR) was traced using Photoshop CS2. SSR parameters (length and thickness), as well as bouton midline area, were measured using NIH ImageJ software; for each midline, the total length of the lines drawn (length of SSR) and the length of the cross sections (for the detail, see supplemental Fig. S6, available at www. jneurosci.org as supplemental material) were measured. For measurements of synaptic length, 28 synapses from 3 control samples, 50 synapses from $6 \mathrm{dlg}{ }^{X I-2}$ samples, 45 synapses from $10 \mathrm{dlg} A^{40-2}$ samples, and 47 synapses from $6 \mathrm{dlgS97^{5 }}$ samples were measured using ImageJ. For measurements of SSR and synaptic bouton area, five $w t$, seven $d g^{X I-2}$, eight $d \lg A^{40-2}$, and six $d \lg S 97^{5}$ bouton midlines were analyzed. For measurements of internal vesicle diameter, EM pictures were scanned at high resolution. Overall, $19 w t$ boutons, $22 \mathrm{dlg}^{X I-2}$ boutons, $23 \mathrm{dlg} A^{40-2}$ boutons, and $21 \mathrm{dlg} S 97^{5}$ boutons were analyzed. For each bouton in the above genotypes, the internal diameter of at least 20 vesicles was measured.

\section{Electrophysiology}

Electrophysiological recordings were done as previously described by Ashley et al. (2005). For each muscle recorded, the resting membrane potential, input resistance, and specific capacitance were measured. 
Seven samples for the mutant $d \mathrm{lg}^{\mathrm{XI}-2}$, eight for $C S$ and $\operatorname{dlg} A^{40.2}$, and nine for $\operatorname{dlg} S 97^{5}$ were analyzed.

\section{Behavioral tests}

Climbing assay. Climbing assays were performed using 3-d-old adults in multiple batches of 30-60 flies. The ability to climb against gravity was measured by a countercurrent distribution (Benzer, 1967) and scored as by Xu et al. (2006).

Olfactory assay. Olfactory avoidance responses were measured as described by Anholt et al. (1996) using 1\% benzaldehyde as the repellent odor in groups of five individuals not separated by genre.

Phototaxis assay. Phototaxis assays were performed as described by Benzer (1967) with modifications. Approximately 100 5-d-old males were placed in glass test tubes $(14 \mathrm{~cm}$ long) horizontally for at least $1 \mathrm{~h}$ in an artificially light illuminated room before they were transferred to complete darkness for at least $5 \mathrm{~min}$. A clean tube was then connected to the one containing the flies, and a halogen light $(15 \mathrm{~W})$, as the only light source, was turned on at the end of the empty tube. Flies were allowed to move to the illuminated tube for $1 \mathrm{~min}$, and then the tube was replaced for a new tube. This procedure was repeated four times. The number of flies in each tube was determined.

Courtship behavior assay. Four- to seven-dayold flies kept isolated shortly after hatching were used for the courtship assay. Virgin females of the white Oregon strain were gently introduced into the courtship chamber unanesthetized. The time over which the male was engaged in courtship behavior (orientation toward the female, licking female genitals, wing extension, female following, wing vibration, and attempts to copulate) was measured for $10 \mathrm{~min}$. Males that did not show any courtship behavior during the experiment were discarded from the quantification. The courtship index was calculated as the amount of time spent courting during the $10 \mathrm{~min}$ of the assay divided by 10. Statistical analysis was performed using the WilcoxonMann-Whitney test for unpaired data. Control males were of the strain $y w ;$ UAS-EGFP-dlgS97.

Rhythmicity assays. Locomotor activity was monitored using an automated setup (Trikinetics, Waltham, MA). Experiments were repeated three times, each time including 28-32 individuals. For the average locomotor activity histograms, the activity of each genotype was averaged across $3 \mathrm{~d}$ [days 2-4 of a light/dark (LD) cycle]. For each individual fly, the activity of each $30 \mathrm{~min}$ bin was normalized to the fly total activity during that particular day, averaged over successive days, and an average of the daily averages was obtained. The power fast Fourier transform (FFT) (a measure of the strength of the rhythm) was calculated (Clocklab; Actimetrics, Wilmette, IL). Statistical analysis included ANOVA and pairwise comparisons against the control (original P-element insertion; dlgS97 $7^{N P 7225}$ or elav-Gal4, dlgS97 $7^{138}$ for the rescue experiments) using Dunnett's multiple-comparisons post hoc test.

Electroretinograms. Flies, $10 \mathrm{~d}$ of age or younger posteclosion, were dark-adapted for at least $5 \mathrm{~min}$, and then exposed to a $1 \mathrm{~s}$ pulse of white light $(400-700 \mathrm{~nm}), \log I / I_{0}=-4$ for the first light stimulus and $\log I / I_{0}$ $=-2$ for the second light stimulus; $I_{0}=6600$ lux. Electroretinogram (ERG) recordings were conducted at room temperature using two glass microelectrodes filled with $1 \mathrm{M} \mathrm{NaCl}$. The recording electrode was placed on the surface of the fly eye, while the ground electrode was inserted into the thorax of the fly. White light stimulation was a xenon arc lamp (Lambda LS 175W; Sutter Instruments, Novato, CA) passed through a $400-700 \mathrm{~nm}$ bandpass filter. Signals were sampled at $1 \mathrm{kHz}$ using a Digidata 1322A digitizer (Molecular Devices, Sunnyvale, CA) and filtered using a boxcar smoothing filter (Clampfit; Molecular Devices, Sunnyvale, CA) (5-11 points depending on noise level).

\section{Results}

\section{Generation of specific $d l g A$ and $d l g S 97$ mutants}

Previous studies show that several transcripts are generated from the $d l g$ locus, which would translate into peptides ranging from 27 to $130 \mathrm{kDa}$ (Mendoza et al., 2003) (and Flybase record). However, only two proteins of high molecular weight predominate, DLGA and DLGS97, which result from the use of two different transcriptional start sites (Mendoza et al., 2003) separated by 18 $\mathrm{kb}$ (Fig. 1A,B). To generate specific mutants for the two isoforms, we mobilized P-element insertions (NP7225 and EY5003), located 959 bp upstream from the first translated exon of $d l g S 97$ or $10 \mathrm{bp}$ from the first translated exon of $\operatorname{dlg} A$, respectively (Fig. $1 A)$. This strategy allowed us to isolate specific excision-induced $d \lg S 97$ and $d \lg A$ mutants. From the mobilization of the P-element EY5003, we isolated the excision $d \lg A^{40.2}$, which completely eliminated DLG $_{\mathrm{PDZ}}$ staining in epithelia, leaving DLG $_{\mathrm{S} 97 \mathrm{~N}}$ immunoreactivity in the NMJ undiminished, as determined by Western blots of larval body wall muscles and imaginal discs (Fig. $1 E)$ (data not shown). As expected from the tumor suppression function ascribed to $d l g$ in epithelia (Woods et al., 1996), these larvae have tumorous imaginal discs and enlarged brain, and they die in the third-instar larval stage, similar to dlg mutant alleles.

From the mobilization of the P-element NP7225, we isolated two excision strains, $d \lg S 97^{138}$ and $d \lg S 97^{5}$, in which $\mathrm{DLG}_{\mathrm{S} 97 \mathrm{~N}}$ immunoreactivity was eliminated (Fig. $1 A, C$ ). Both $d l g S 97$ alleles retained DLGA expression as revealed by immunocytochemistry (Fig. 1D) and Western blot assays (Fig. $1 E$ ) using either a monoclonal antibody against the PSD-95/DLG/zona occludens-1 2 (PDZ-2) (anti-DLG ${ }_{\mathrm{PDZ}}, 4 \mathrm{~F} 3$ ) (Parnas et al., 2001) or a polyclonal antibody against the PDZ1 and two domains of DLG (Thomas et al., 1997). $d \lg S 97^{138}$ has a $3.2 \mathrm{~kb}$ deletion that includes exon 1 and most of exon 2 (Fig. $1 A$ ). $d \lg S 97^{5}$ has an $8 \mathrm{~kb}$ deletion, which removes exons $1-3$ and a portion of exon 4 (Fig. $1 A$ ). In both 


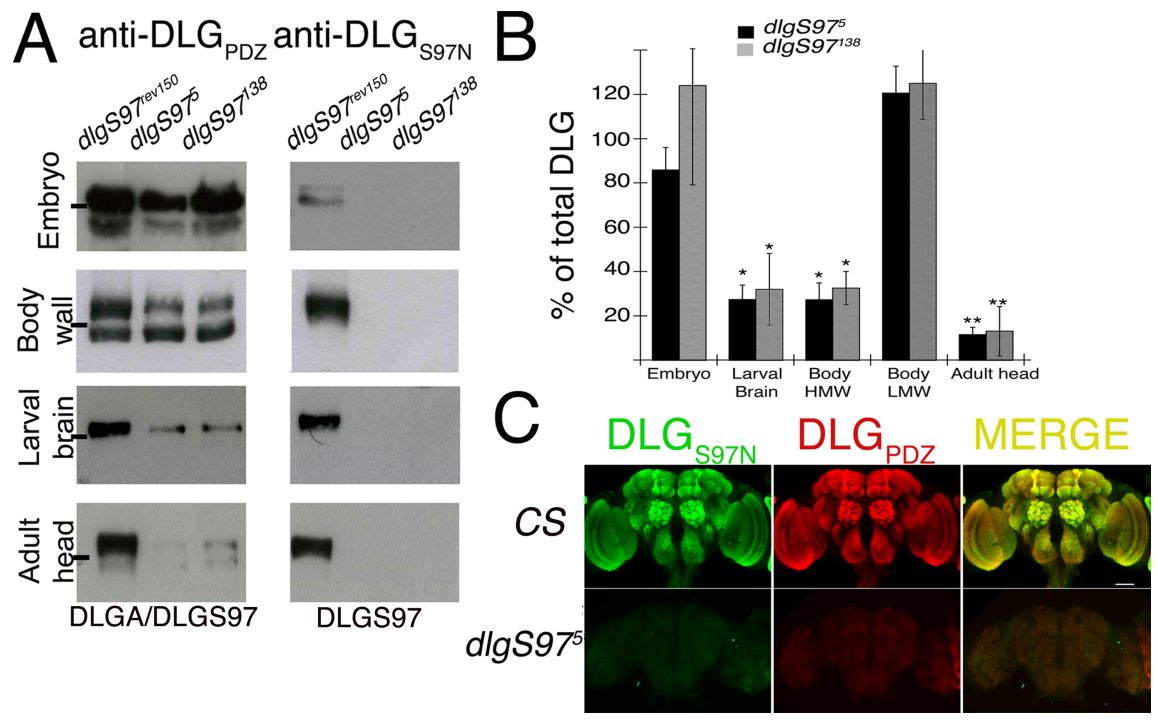

Figure 2. Progressive replacement of DLGA for DLGS97 during development. $A$, Representative Western blots of homogenized tissue of embryo (all stages, approximate MW, $130 \mathrm{kDa}$ ), larval body wall (body wall, approximate MW, 116 and $97 \mathrm{kDa}$ ), larval brain (approximate MW, $130 \mathrm{kDa}$ ), and adult head (approximate MW, $130 \mathrm{kDa}$ ). All blots were tested in parallel with the same concentration of antibody (1:3000, affinity-purified $\mathrm{DLG}_{597 \mathrm{~N}}$, and 1:1500 $\mathrm{DLG}_{\mathrm{PDZ}}$ ). The load was as follows: $30 \mu \mathrm{g}$ for embryos, and the equivalent to one larval body wall, six larval brains, and one head per lane. The line at left in each blot points the position of the $116 \mathrm{kDa}$ molecular weight standard. $\boldsymbol{B}$, Quantification of total DLG label of at least three independent Western blot assays

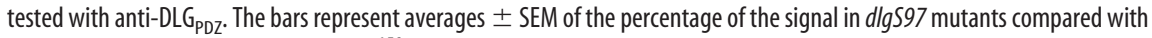
the signal of the control strain $d 19 S 97^{\text {rev } 150}$, at different developmental stages. Body HMW, Larval body wall high molecular weight band (116 kDa); body LMW, larval body wall low molecular weight band $(97 \mathrm{kDa}) .{ }^{*} p<0.05 ;{ }^{* *} p<0.01$. C, DLG proteins in adult brain. Confocal images (compose of 17 slices) of WT (top panel) and dlgS97 mutant (bottom panel) adult brain labeled with $\mathrm{DLG}_{\mathrm{PDZ}}$ or $\mathrm{DLG}_{597 \mathrm{~N}}$ antibodies and the merged image showing the complete overlapping of the labeling patterns and the strong decrease in intensity of the labeling to DLG $G_{\mathrm{PDZ}}$. Note that $\mathrm{DLG}_{\mathrm{PDZ}}$ antibody labels both DLGA and DLGS97 proteins.

mutants, a portion of the sequence encoding the peptide recognized by the DLG $_{\mathrm{S} 97 \mathrm{~N}}$ antibody (exons $1-6$ ) (Fig. $1 B$ ) is still present, but a protein of a lower molecular weight is not detected by Western blots, confirming that they are null $\mathrm{dlgS} 97$ mutants. As genetic controls, we also isolated a precise excision of the P-element, $d \operatorname{lgS} 97^{\text {rev150 }}$, which has normal DLGS97 and DLGA expression (Fig. 2 A). These mutants are viable and do not exhibit tumors.

Our previous results suggested a profound role for DLGS97 in the development of the nervous system based on dsRNA injection. However, we discovered later that these defects were attributable to off-target effects of a $50 \mathrm{bp}$ stretch within the $1.2 \mathrm{~kb}$ dsRNA used for these experiments (Mendoza et al., 2003). The lack of developmental abnormalities we observe in null $\mathrm{dlgS97}$ mutants at embryonic stage (supplemen-tal Fig. S1, available at www.jneurosci.

org as supplemental material), the preponderance of DLGA at this developmental stage, and the full viability of $d \operatorname{lgS} 97$ mutants to adult stages, are consistent with a nonessential role of DLGS97 in nervous system development.

\section{Expression of DLGA and DLGS97 is developmentally regulated}

The isolation of null $d \lg S 97$ mutants allowed us to examine the expression of DLGA, for which specific antibodies are not available. In embryos, despite the complete lack of DLGS97, there is not a significant decrease in $D_{L} G_{\mathrm{PDZ}}$ immunoreactivity (Figs. $1 D, 2 A, B)$, suggesting that DLGA is the main $d l g$ product expressed in the embryonic nervous system and somatic muscle. At the wild-type (WT) larval body wall, two characteristic bands are revealed by anti-DLG $\mathrm{PDZ}_{\mathrm{P}}$ antibodies [a $116 \mathrm{kDa}$, high molecular weight (HMW) band also recognized by $\mathrm{DLG}_{\mathrm{S} 97 \mathrm{~N}}$ antibody and a $97 \mathrm{kDa}$, low molecular weight (LMW) band]. In $d \operatorname{lgS} 97$ mutants, the HMW band show a 70\% reduction in DLG PDZ $_{\text {immunoreactivity }}$ levels, but no reduction in the LMW band is observed (Fig. $2 A, B$ ). This, together with the elimination of the LMW band in $d l g A$ mutants (Fig. $1 E$ ), confirms that the LMW band corresponds exclusively to DLGA. DLG ${ }_{\mathrm{PDZ}}$ immunoreactivity is reduced by $70 \%$ in the larval and $90 \%$ in the adult CNS (Fig. $2 A, B$ ), which indicates that DLGS97 is the predominant variant in both the adult and the larval brain. Thus, the expression of $d l g$ isoforms is developmentally regulated, with the DLGS97 isoform becoming increasingly dominant in the adult brain and the DLGA isoform being preponderant during embryonic development.

$d l g$ protein products are expressed in the adult brain, particularly in the visual centers (lobula plate, medulla, and lamina), the mushroom bodies, and the antennal lobes (Rogero et al., 1997; Ruiz-Canada et al., 2002). However, the lack of an adult viable null mutant has precluded the analysis of their function in adult brain function.

Our Western blot studies demonstrated that DLGS97 predominates in the adult brain (Fig. $2 A, B$ ). To determine whether there is differential localization of the two main $d l g$ products, we labeled the brain structures with the available DLG antibodies. No difference in the brain structures labeled by $\mathrm{DLG}_{\mathrm{PDZ}}$ and $\mathrm{DLG}_{\mathrm{S} 97 \mathrm{~N}}$ antibodies was detected (Fig. 2C). In dlgS97 mutants, there is a strong decrease in the immunoreactivity to $\mathrm{DLG}_{\mathrm{PDZ}}$, consistent with the results obtained by the Western blot analysis; a very low level of DLG $_{P D Z}$ reactivity is detectable only in the lamina, mushroom bodies, and antennal lobes, the regions in which total DLG is higher in the WT (Fig. 2C). Thus, in dlgS97 mutants, the remaining DLG $(<10 \%$ by Western blots) is distributed in a pattern similar to the WT. Thus, dlgS97 mutants constitute an excellent tool to investigate the role of the main synaptic MAGUK expressed in the Drosophila adult brain.

\section{Behavioral consequences of the loss of DLGS97}

To explore the function of the adult brain in the absence of DLGS97, we first centered our analysis in simple behaviors such as locomotion, odor, and light perception. To evaluate locomotion, we measured the ability of flies to climb against gravity (Benzer, 1967; Xu et al., 2006). No significant difference between dlgS97 alleles and controls is observed (Fig. $3 A$, left panel). To assess odor perception, we performed an "olfactory avoidance assay" (Anholt et al., 1996). Again, no differences in avoidance responses between $d \operatorname{lgS} 97$ mutants and controls are observed (Fig. $3 A$, right panel).

The function of the visual system in the mutants was examined by testing the natural ability of the flies to go toward light in a "phototaxis assay" (Benzer, 1967). Whereas $\sim 30 \%$ of control flies remained in the dark in the first minute, this number was more than doubled (to $\sim 70 \%$ ) in $d \operatorname{lgS} 97^{138}$ and $d \operatorname{lgS} 97^{5}$ mutants 


\section{A Locomotor and olfactory assays}
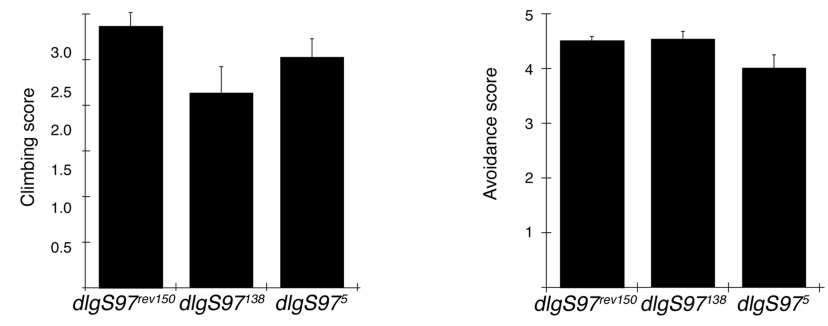

B Phototaxis assay

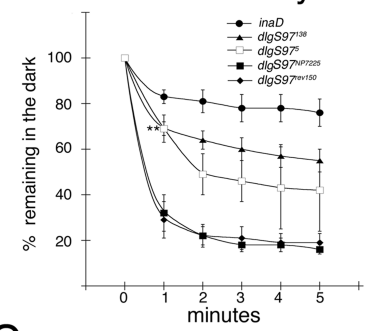

C Retinal response

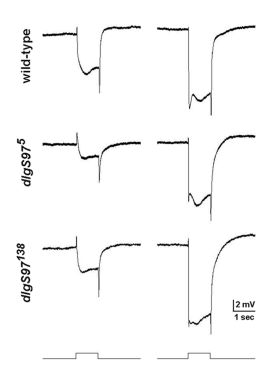

phototaxis defect, only a partial rescue is observed with DLGA (Fig. $3 B$, right panel).

The defects on phototaxis are not likely attributable to defects in locomotion or coordination, as demonstrated by the normal climbing assay in $\mathrm{dlgS} 97$ mutants, and may arise from defects in phototransduction, or visual processing. However, ERG recordings in dlgS97 mutants show normal kinetic and sensitivity parameters (Fig. $3 C$ ), suggesting that defects in phototransduction or synaptic transmission at the retina are unlikely to underlie the phototaxis deficit in these mutants. Thus, although locomotor activity, odor perception, and phototransduction do not require DLGS97, a more complex behavior, such as phototaxis, that requires the coordination of more than one motor-sensory pathway was altered in $d l g S 97$ mutants.

\section{Requirements of DLGS97 during courtship behavior}

These observations led us to examine other behaviors involving coordination of multiple sensory pathways, including male courtship behavior. We measured the courtship index defined as the fraction of time that a male spends courting a virgin female over a 10 min period (Gaines et al., 2000). We found that both courtship index and mating were disrupted in $d \lg S 97^{5}$ mutants. dlgS97 mutant males spend 40\% less time than control males courting a wild-type virgin (Fig. 3D). In addition, whereas $80 \%$ of control males mate after courtship during the test period, only $22 \%$ of $d \operatorname{lgS} 97$ mutant males mate during this period (supplemental Table 1, available at www.jneurosci.org as supplemental material). Notably, the abnormal phenotypes are completely rescued by neuronal expression of the dlgS97 transgene, but no rescue is observed by expressing the $\operatorname{dlg} A$ transgene (Fig. 3D; supplemental Table 1, available at www.jneurosci.org as supplemental material). Thus, $d l g$ is important for proper courtship behavior and mating, and this function depends exclusively on the DLGS97 isoform. These observations highlight a differential use of DLG isoforms in different contexts.

ldehyde oder trols. Bars \pm SEM represent the average of $9-21$ (climbing score) and 11-19 (odor detection) independent experiments. $\boldsymbol{B}$, Phototaxis assay showing the percentage of flies remaining in the dark. Left, Comparison between controls, dlgS97 mutants, and inaD mutants showing that dlgS97 mutants have phototaxis defects that are not statistically different from inaD mutants and different from controls. Each point corresponds to the average of three independent experiments \pm SEM. Right, The mutant defects in phototaxis are completely rescued by neuronal expression of DLGS97, but only partially rescued by the expression of DLGA. C, ERGs from wildtype, $d l g S 97^{5}$, and $d l g S 97^{138}$ flies. The stimulus was a $1 \mathrm{~s}$ sulse of white light $(400-700 \mathrm{~nm}), \log$ $I / I_{0}=-4$ for the first light stimulus and $\log I / I_{0}=-2$ for the second light stimulus; $I_{0}=6600$ lux, at the time indicated beneath the recordings. Note the lack of differences between wild type and mutants. $\boldsymbol{D}$, Courtship index of individual control and $d l g 597^{5}$ males showing that courtship behavior is defective in the mutant, and that this phenotype can be rescued by neuronal DLGS97 but not by DLGA expression. The horizontal lines represent the median of each group. Levels of significance were determined by a two-tail Student's $t$ test in $\boldsymbol{A}$ and $\boldsymbol{B}$ and by a WilcoxonMann-Whitney test in $\boldsymbol{D}\left({ }^{*} p<0.05\right.$ and $\left.{ }^{* *} p<0.01\right)$.

(Fig. 3B, left panel). To compare the magnitude of this phenotype with the one in mutants with severe defects in phototaxis, we performed this assay with inaD mutants. These mutants show defects in the phototransduction cascade because of the lack of the scaffolding protein INAD (Tsunoda et al., 1997). Approximately $80 \%$ of inaD mutant flies remain in the dark in the first minute, and this number was not statistically different from that in $d \lg S 97$ mutants (Fig. 3B).

To explore the $d l g$ isoform-specific requirement for phototaxis, we performed rescue experiments, in which either a DLGA or a DLGS97 transgene was expressed pan-neuronally in the dlgS $97^{138}$ mutant background (the strongest of both phenotypes). Although expression of DLGS97 completely rescues the

\section{DLGS97 is required for circadian activity}

Circadian variation in locomotor activity results from the concerted action of several neuronal pathways in the brain (HelfrichForster, 2003). Therefore, we monitored rest-activity cycles of young control and dlgS97 mutants. Wild-type flies show increased activity near dawn and dusk, remaining quiescent the rest of the day under synchronized conditions (LD cycles). These bursts of locomotor activity are the result of two processes, the clock-controlled anticipation of the upcoming environmental transition, giving rise to the so-called morning peak, and the startle effect, an immediate behavioral response to lights $\mathrm{ON} /$ OFF, which is still present in clockless mutants, such as per $^{\circ}$ (Wheeler et al., 1993) (Fig. 4A, gray arrows). This rhythmic behavior is maintained for many days when flies are transferred to constant darkness (DD) (Fig. 4A, gray arrows), highlighting its endogenous control. Representative actograms of dlgS97 mutants along with the control are shown in Figure 4A. Although $d \operatorname{lgS} S 7^{138}$ and $d l g S 97^{5}$ flies are capable of synchronizing their locomotor activity to LD cycles, average activity plots depicting the normalized activity of a group of flies indicated that both $\mathrm{dlgS} S 97^{5}$ and $d l g S 97^{138}$ mutants display a defective morning peak (supplemental Fig. S2, red arrowheads; available at www.jneurosci.org as supplemental material). Consequently, the activity of $d \operatorname{lgS} 97 \mathrm{mu}-$ tants is not consolidated to the subjective day under free-running conditions (what would have been daylight under a regular LD cycle, after gray arrows in Fig. $4 \mathrm{~A}$ ) resulting in a gradual loss of rhythmicity. We calculated the mean power FFT (a measure of 


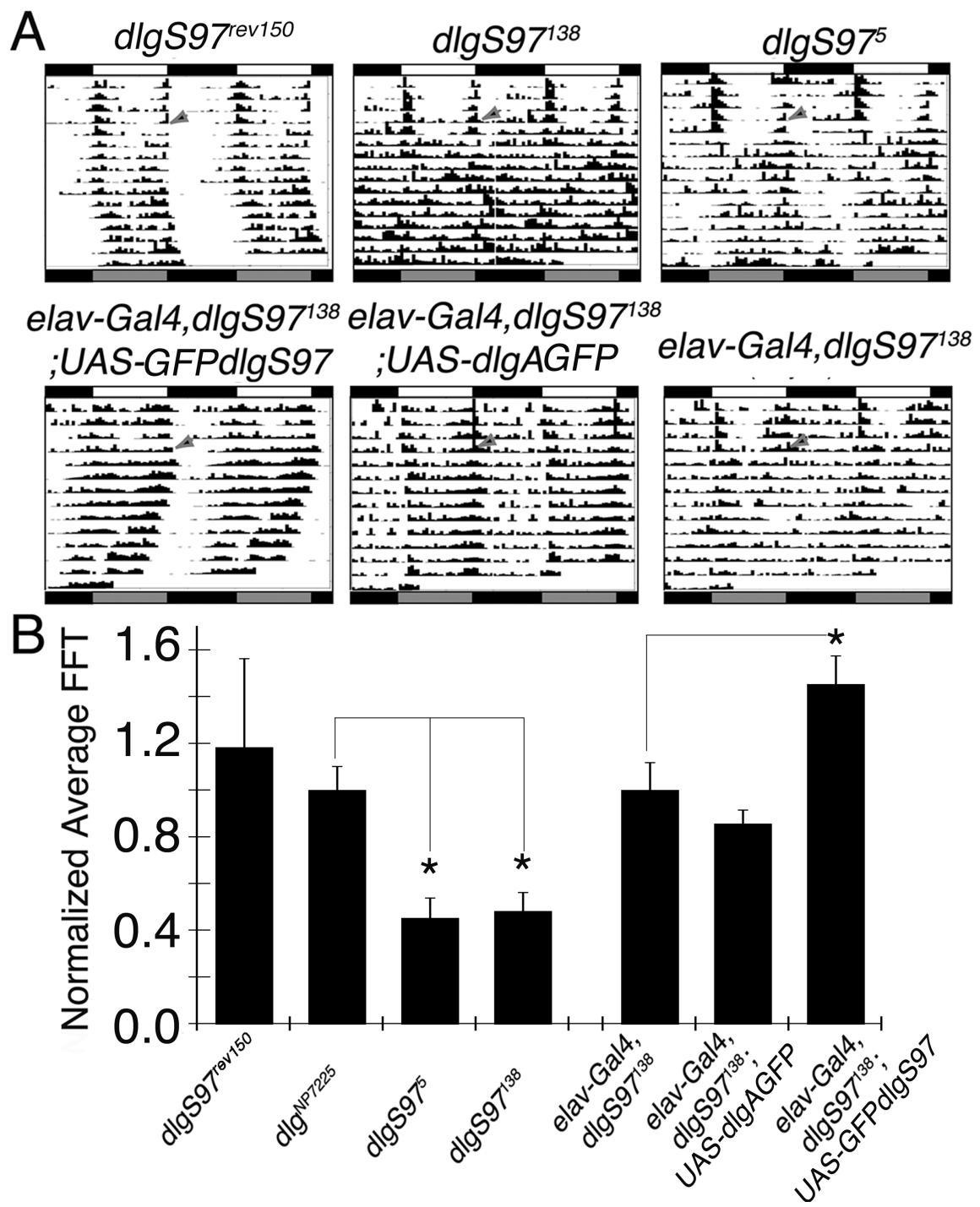

Figure 4. Abnormal circadian activity rhythms in $\operatorname{dlg}$ mutants. $\boldsymbol{A}$, Representative double-plotted actograms for the indicated genotypes. The gray arrows indicate the day of transfer to constant conditions (DD). The black and white boxes at the top of the actograms indicate night and day phases, respectively. The black and gray bars at the bottom of actograms indicate subjective night and day respectively. $\boldsymbol{B}$, Power FFT (a measure of the strength of the rhythm) in the different genotypes. Note that dlgS97 mutants exhibit unconsolidated rhythmic behavior that is significantly improved by the expression of DLGS97, but not of DLGA in all neurons. The power FFT was calculated using the Clocklab software (Actimetrics). Statistical analysis included ANOVA and pairwise comparisons with the original P-element insertion (the control dlgS97 ${ }^{N P 7225}$ strain) or the recombinant strain elav-Gal4, $d l g S 97^{138}$ for the rescue experiments, using Dunnett's multiple comparisons post hoc test $\left(^{*} p<0.05\right)$. Error bars indicate SEM.

the strength of the underlying rhythm) for control and mutant lines and confirmed that both $d \lg S 97^{138}$ and $d \lg S 97^{5}$ performed poorly under this behavioral paradigm (Fig. $4 B$ ). In contrast, the revertant strain $d \operatorname{lgS} 97^{\text {rev150 }}$ and the P-element insertion NP7225 display normal behavior under free-running conditions (Fig. 4). To determine the specific requirements for DLGA and DLGS97 in the rhythmicity defects observed, we monitored the activity of dlgS97 mutants expressing DLGS97 or DLGA in all neurons (Fig. $4 B$ ). Only flies expressing DLGS97 are able to maintain a rhythmic behavior in DD condition, whereas DLGA-expressing flies were not different from the control. This highlights the specific need of DLGS97 for this behavior.

DLGA and DLGS97 are differentially used at larval NMJs in a context-specific manner

The results presented above indicate a marked difference in the expression pattern and functional requirements for DLGA and
DLGS97 in the embryonic versus the adult nervous system. Thus, although DLGS97 is not required for basic behaviors, more complex processes such as phototaxis, courtship, and circadian rhythms require DLGS97 for proper behavioral display. Furthermore, courtship behavior appears to have a unique requirement for the DLGS97 isoform, because mutant defects are not rescued by expressing the $\operatorname{dlg} A$ transgene. These isoform- and developmental-specific requirements led us to ask whether DLGA and DLGS97 were also differentially required at intermediate, larval stages, and in particular in the NMJ, where the two variants coexist, and most of the studies about the role of $d l g$ products have been conducted. This was addressed by examining the influence of the selective mutations in $\operatorname{dlg} A$ or $\operatorname{dlg} S 97$ in the structure and function of this glutamatergic synapse.

Previous studies, using $d \lg$ mutations that severely decrease both DLGA and DLGS97, have demonstrated that DLG proteins have fundamental functions in the development and morphological plasticity of the larval NMJ as well as in synaptic function (Ataman et al., 2006). Although DLG PDZ $_{\text {immunoreactivity }}$ (recognizing both DLGA and DLGS97) is completely eliminated in epithelial cells of $\lg A^{40.2}$ mutant larvae (data not shown), PDZ staining at the NMJ is not significantly reduced (Fig. 5), and DLG $_{\text {S97N }}$ immunoreactivity is upregulated in this mutant in $~ 50 \%$ (Fig. 5). In contrast, in $d \operatorname{lgS} 97$ mutants, where NMJs completely lack DLG S97N $_{\text {immunoreac- }}$ tivity, only a partial (20\%) decrease in DLG $_{\mathrm{PDZ}}$ immunoreactivity is observed (Fig. 5B, first panel). Together, these observations suggest that (1) both DLGS97 and DLGA coexist in the WT NMJ at approximately the same level of expression, (2) when DLGA is eliminated, DLGS97 is upregulated to WT levels of total DLG (DLGA plus DLGS97) (Fig. 5B), and (3) when DLGS97 is eliminated, there is an upregulation of DLGA but this upregulation does not completely reach WT levels because total DL$\mathrm{G}_{\mathrm{PDZ}}$ immunoreactivity is still decreased by $20 \%$ (Fig. $5 B$ ).

We studied the expression of FasII and Scrib, two synaptic proteins whose localization depends on $d \lg$ (Thomas et al., 1997; Mathew et al., 2002). Selective mutations in either $\operatorname{dlg} S 97$ or $d \lg A$ causes abnormal localization of FasII around synaptic boutons, although this phenotype is not as strong as that observed in the $\mathrm{dlg}^{X I-2}$ allele (Thomas et al., 1997), which affects both the DLGA and DLGS97 isoforms (Fig. 5; supplemental Fig. S3, available at www. jneurosci.org as supplemental material). Thus, both $d \lg S 97$ and $d \lg A$ appear to be required for normal FasII localization at the NMJ.

Scrib is a scaffolding protein of the LAP (LRR and PDZ) family, which like DLG and FasII is localized at both presynaptic and postsynaptic sites at the NMJ, and which interacts with DLG 
through GUK-holder (Mathew et al., 2002). Elimination of either DLGS97 or DLGA alone has little impact on Scrib localization (Fig. $5 A$ ), suggesting that in this case either isoform can completely compensate for the lack of the other.

DLG isoform-specific function was also tested by examining the structure and function of the NMJ in both $d \lg S 97$ and $\operatorname{dlg} A$ mutants. Active zones at the larval NMJ are composed of two structural elements, the T-bars, which regulate the efficiency or the synchrony of evoked neurotransmitter release (Kittel et al., 2006), and the presynaptic density (PRD), a region of the presynaptic membrane with increased electron density, exactly apposed to the postsynaptic density (PSD), and thought to be the site for synaptic vesicle fusion (Prokop, 2006) (Fig. 6A,D). Mutations in $d l g$ lead to an increase in the number of T-bars (Lahey et al., 1994). We found that, in both $d \lg S 97$ and $d \lg A$ mutants, there is a significant increase in the length of the PRD (Fig. 6D, $F, G$ ). Interestingly, this phenotype is of the same magnitude as in $d \lg ^{X I-2}$ mutants, suggesting that both isoforms collaborate in the regulation of active zone structure, and that neither is sufficient for this regulation.

Another notable phenotype in $d l g$ mutants is the presence of a highly reduced SSR (Lahey et al., 1994). The SSR is a complex membrane structure that expands gradually during larval development and that is thought to play a variety of roles, including postsynaptic protein localization, and local translation (Ataman et al., 2006). Notably, no changes in SSR structure when normalized to bouton size are observed in either mutant (Fig. 6G, middle panel), suggesting that either $d l g$ isoform is sufficient for normal SSR development. Intriguingly, however, analysis of the SSR thickness revealed that, although a reduction in SSR thickness is observed in $d l g^{X I-2}$ mutants, no such difference is observed in $d \lg A^{40.2}$ and $d \lg S 97^{138}$ mutants (Fig. $6 B, C, E, G$ ). Furthermore, SSR thickness is significantly increased in $d \operatorname{lgS} 97^{5}$ mutants (Fig. $6 E, G$, right panel). Thus, DLGA and DLGS97 can compensate, or even overcompensate in the case of $d \operatorname{lgS} 97^{5}$, for each other in the regulation of SSR length and thickness.

Because we detected both form-specific as well as redundant functions for the two DLG variants, we next studied the NMJ synaptic transmission in $d l g A$ and $d l g S 97$ mutants. This was examined by measuring the amplitude and frequency of spontaneous miniature excitatory junctional potentials (mEJPs), and evoked responses (EJPs) on motor-nerve stimulation. We compared synaptic transmission of the most severe allele $d \mathrm{lg}^{\mathrm{XI-2}}$ with $d \lg A$ and $d \lg S 97$ null mutants. $d l g^{X I-2}$ has a significant decrease in evoked responses, and a similar decrease is observed in the $d l g A$ mutant. However, responses are indistinguishable from wild type in the $d l g S 97$ mutant allele (Fig. $7 B, F$ ). In contrast, a significant increase in the amplitude of mEJPs is observed in $d g^{X I-2}$ and $d \lg S 97$ but not in $d \lg A$ mutants (Fig. $7 A, C$ ) without change in frequency in all mutant lines (Fig. 7D). Overall, quantal content is depressed in all mutant combinations (Fig. 7G), suggesting synaptic transmission defects in all the genotypes. The increased amplitude of the mEJPs may be attributable to an increase of the size of the vesicles as it was described for $d l^{m 52}$ mutants (Karunanithi et al., 2002) or to an increase in the density or size of the glutamate receptor clusters. To differentiate between these alternatives, we evaluated the sizes of the synaptic vesicles and the density and size of glutamate receptor clusters. The size of vesicles in CS (internal diameter, $21.72 \pm 2.1 \mathrm{~nm}$; average $\pm \mathrm{SD}$ ) shows differences with all the mutants; $d l g^{X I-2}$ mutant $(29.2 \pm 1.99 \mathrm{~nm})$, $d \lg A^{40.2}(26.4 \pm 3.67 \mathrm{~nm})$, and $d \lg S 97^{5}(27.03 \pm 2.82 \mathrm{~nm}) \mathrm{mu}-$ tants; $p<0.001$ for all mutants. These vesicle sizes are in agreement with those reported in the literature for internal diameters (Karunanithi et al., 2002). However, the density and size of glutamate receptor clusters is increased only in $d \operatorname{lgS} 97$ mutants $(p<$ 0.05 ) and not in $d l g{ }^{X I-2}$ or $d l g A^{40.2}$ mutants (supplemental Fig. S4, available at www.jneurosci.org as supplemental material).

These results show that, although DLGA and DLGS97 have some redundant functions at the NMJ, normal synaptic transmission requires specific functions of each form.

\section{Discussion}

The study of the expression and function of the main Drosophila synaptic MAGUKs reported here brings about four significant conclusions. (1) The expression of $d l g$ products in the nervous 


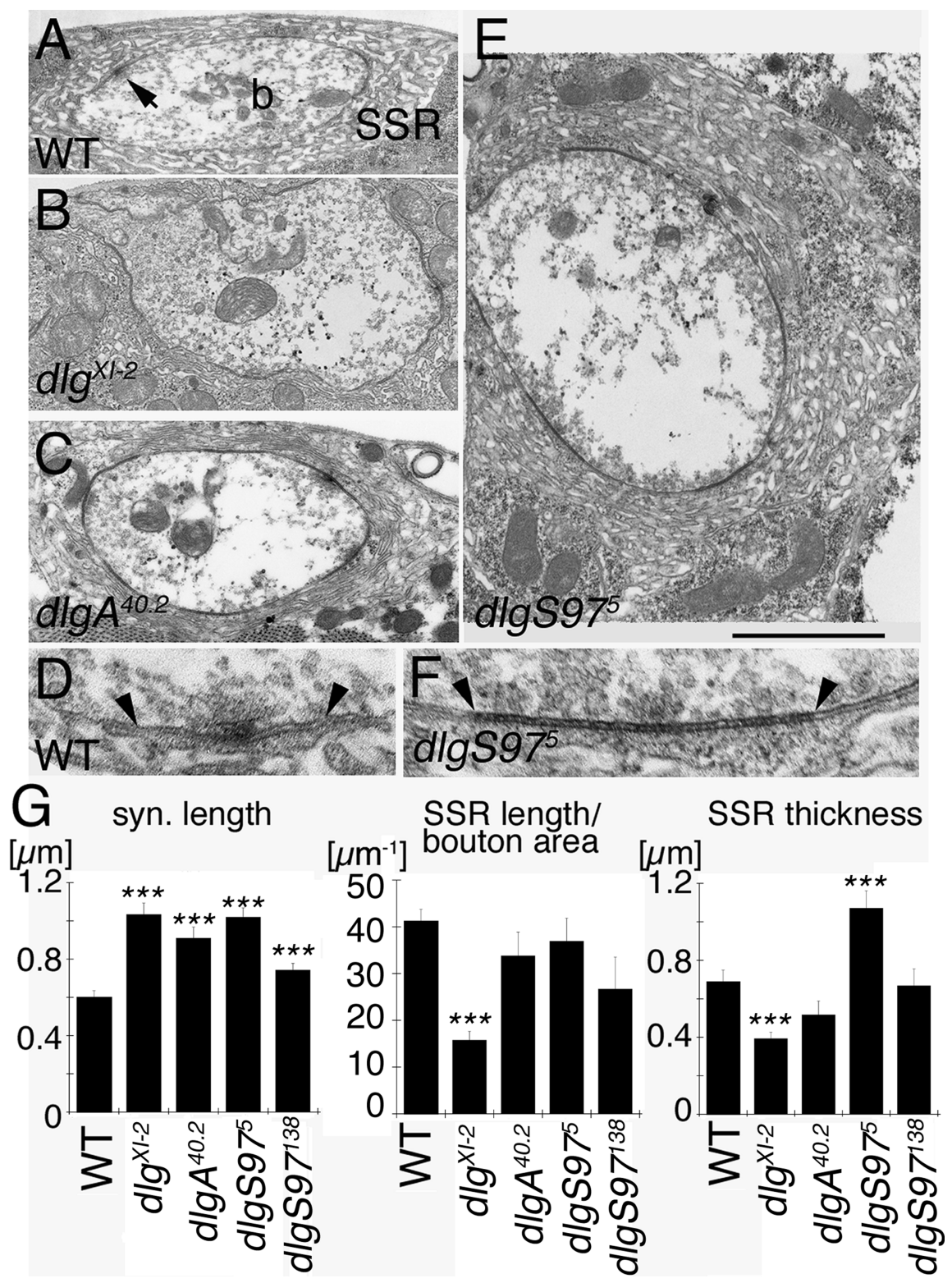

Figure 6. Ultrastructure of synaptic boutons in $\mathrm{dlg}$ mutants. $\boldsymbol{A}-\boldsymbol{C}$ and $\boldsymbol{E}$ show TEM micrographs of type lb boutons at muscle 6 or 7 (abdominal segment 3) of third-instar (A) wild-type, $(\boldsymbol{B}) d l g^{X 1-2},(\boldsymbol{C}) d l g A^{40.2}$ and $(\boldsymbol{E}) d l g S 97^{5}$ larvae. b, Bouton. The arrow in $\boldsymbol{A}$ points to an active zone. $\boldsymbol{D}, \boldsymbol{F}$, High-magnification views of a representative active zone in wild-type $(\boldsymbol{D})$ and $d / g S 97$ mutants $(\boldsymbol{F})$. The arrowheads indicate the outer limits of the active zone. $\mathbf{G}$, Morphometric analysis of synaptic boutons showing synaptic length (left panel), normalized SSR length (middle panel), and SSR thickness (right panel). Note that active zones are increased in length in $\mathrm{dlg}$, dlgS97, and dlgA mutants, but normalized SSR length is decreased only in $\mathrm{dlg}{ }^{X I-2}$. Scale bar: $\boldsymbol{A}-\boldsymbol{C}, \boldsymbol{E}, 1.2 \mu \mathrm{m} ; \boldsymbol{D}, \boldsymbol{F}, 0.3$ $\mu \mathrm{m}$. For a comparison of $d l g S 97^{5}$ with $d l g S 97^{138}$ mutant allele in other parameters, see supplemental Table 2 (available at www.jneurosci.org as supplemental material).

system is developmentally dynamic; (2) during nervous system morphogenesis, DLGA is the main variant, suggesting that the lack of this form is responsible for the severe developmental defects observed on the elimination of both maternal and zygotic $d l g$ (Perrimon, 1988). (3) DLGS97 is the main variant in the adult brain, and mutations in $\mathrm{dlgS} 97$ do not cause detectable morphogenesis defects, but rather alterations in complex behaviors, implicating DLGS97 in activity of complex synaptic networks. (4) At intermediate developmental stages, in a synapse where both isoforms coexist, DLGA and DLGS97 play overlapping as well as differential roles that can be summarized as follows: (1) both isoforms are redundant, compensating for the absence of the other; (2) both isoforms are required; therefore, the presence of one cannot completely compensate for the absence of the other; (3) a single isoform is required, and thus the absence of the other has no noticeable effects. These findings demonstrate the complexity and versatility of MAGUK family members, and highlight the notion that specific MAGUKs can perform different nonoverlapping functions when present in the same cell, and even in the same cellular compartment.

In mammals, the four SAP genes are either partially redundant, or mutations in single genes result in early lethality, which has hampered assessing the significance of this diversity for synapses and behavior in vivo. Our ability to individually eliminate SAPs in the intact organism provides a powerful tool to begin to understand this diversity. Based on our findings, it is tempting to speculate that, although DLGA has a preponderant function in establishing the nervous system and ensuring proper organization of synaptic connections, DLGS97 might be most relevant in modulating the function of complex neuronal networks. Nevertheless, our studies at the larval NMJ also emphasize the fact that there is relevant overlap in the function of both isoforms when operating in the same cell.

The significant differences in the roles of DLGA and DLGS97 correlate with a single molecular change, the presence of an extended L27-containing N-terminal sequence in DLGS97. It is of high interest to understand the mechanisms linking this discrete molecular difference to the function of the entire system.

Although the in vivo function of the L27 domain of DLGS97/SAP97 in neurons is not fully understood, it has been implicated in AMPA receptor trafficking (Nakagawa et al., 2004), in the synaptic localization of Dlin-7 (Bachmann et al., 2004), in activity-dependent redistribution of AMPA receptors to spines (Mauceri et al., 2004), and in postsynaptic clustering (Chetkovich et al., 2002). L27 domains are found in proteins of the MAGUK family and in proteins of the LIN-7 family and have been widely implicated in the homo-oligomerization and hetero-oligomerization of these scaffolding proteins (Marfatia et al., 2000; Nakagawa et al., 2004; Petrosky et al., 2005). The L27 domain of DLGS97 could coordinate the function of many multiprotein complexes, consisting of a scaffolding protein and all its binding partners. In vertebrates, SAP97 associates through its L27 domain with the first L27 of CASK, which in turn associates through its second L27 to the L27 of LIN-7/MALS (Lee et al., 2002; Feng et al., 2004). The existence of a similar complex in flies is supported by the presence of CASK (CAKI) and LIN-7 (dLIN-7) homologues and the in vitro interaction between CAKI and the L27 of DLGS97 (Lee et al., 2002). CAKI is expressed in a pattern similar to DLG in adults and caki mutants, like dlgS97 

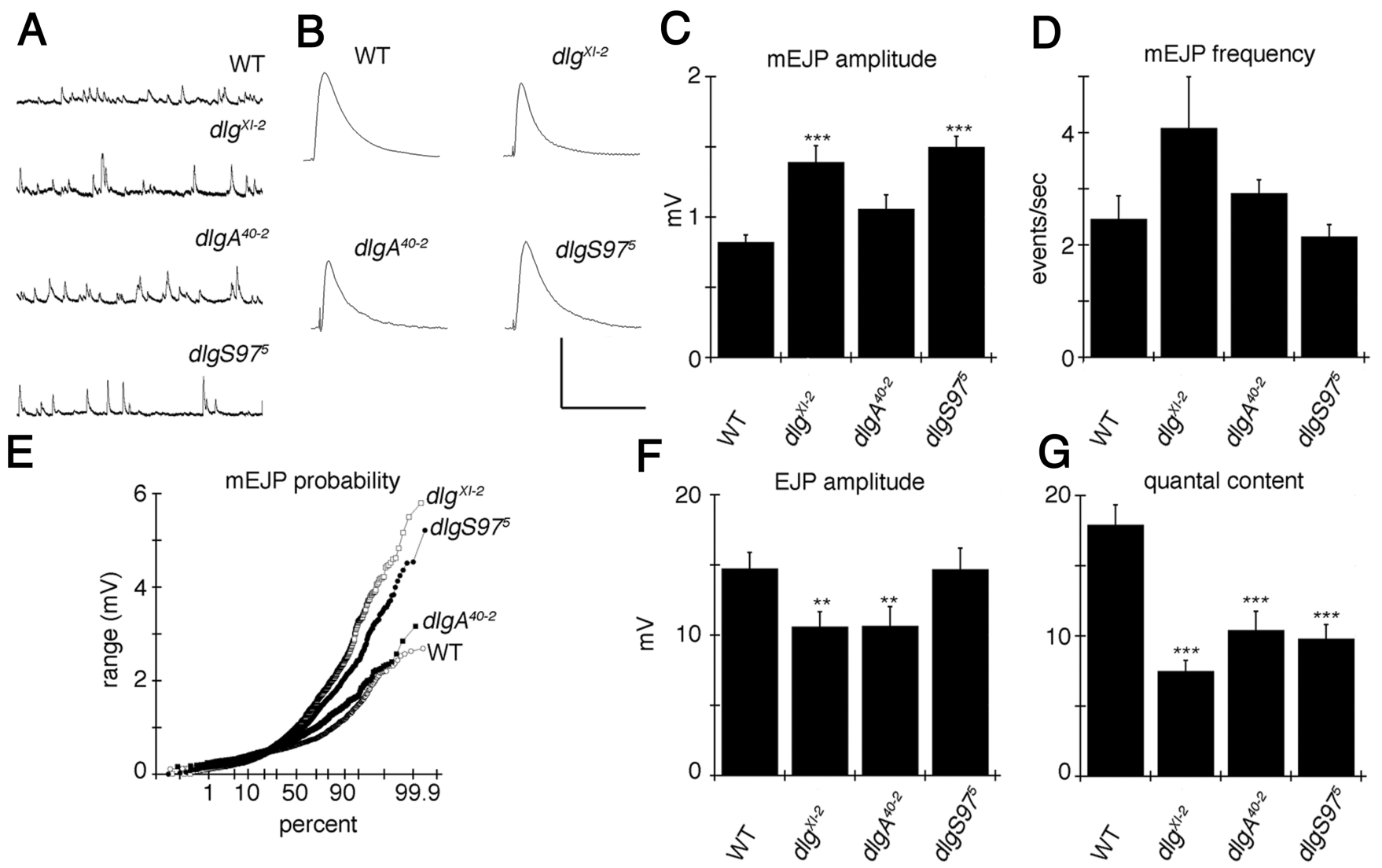

Figure 7. Electrophysiological analysis of $d l g$ mutants. $\boldsymbol{A}, \boldsymbol{B}$, Voltage recordings of muscle 6 in wild-type and $d l g$ mutants, showing representative traces of $m E J P s(\boldsymbol{A})$, and evoked responses (EJP) (B). Calibration: $\boldsymbol{A}, 6.5 \mathrm{mV}, 1.7 \mathrm{~s} ; \boldsymbol{B}, 10 \mathrm{mV}, 125 \mathrm{~ms} . \boldsymbol{C}, \boldsymbol{D}, \boldsymbol{F}, \boldsymbol{G}$, Histograms showing the average \pm SEM of mEJP amplitude ( $\boldsymbol{C}$, mEJP frequency (D), EJP amplitude $(\boldsymbol{F})$, and quantal content (G). $\boldsymbol{E}$, $\mathrm{mEJP}$ amplitude cumulative distribution. Average \pm SEM of the resting membrane potential (in millivolts) and input resistance (in kiloohms $\cdot$ square centimeter) was $62.14 \pm 0.96$ and $6.35 \pm 0.61$ for CS, $63.38 \pm 0.6$ and $6.2 \pm 0.53$ for $\mathrm{dlg}^{X \mid-2}, 63.45 \pm 0.66$ and $6.11 \pm 0.58$ for $\mathrm{dlg} \mathrm{A}^{40.2}$, and $63.33 \pm 0.41$ and $6.39 \pm 0.61$ for $\mathrm{dlg} \mathrm{S} 97^{5}$, respectively; no significant differences between genotypes were detected. Statistical analysis for the frequency, EJP amplitudes, and quantal contents was conducted using Student's $t$ test $\left({ }^{* *} p<0.01 ;{ }^{* * *} p<0.001\right)$. Statistical analysis for the mEJP amplitude cumulative curves was conducted using a Kolmogorov-Smirnov test.

mutants, are viable. These mutants show locomotor speed defects (Martin and Ollo, 1996) and abnormal optomotor behavior (Zordan et al., 2005), although no other behaviors have been examined. CAKI has also been suggested to be involved in the regulation of the autonomous activity of CaMKII regulating its activation and deactivation and shown to be important for the male habituation behavior during mating ( $\mathrm{Lu}$ et al., 2003). In vertebrates, SAP97/CASK/VELI complex has been implicated in the transport of glutamate receptors (Wu et al., 2002) as well as in the recruitment of SAP97 to the membrane (Lee et al., 2002). Thus, DLGS97 is likely to form supramolecular complexes, in which the specific function of lower order complexes is harmonized and perhaps synchronized. The observation that DLGS97 appears to play a role in behaviors that require multiple sensory and motor pathways makes the speculation that DLGS97 control the coordination of complexes involved in the regulation of CaMKII activity and/or the delivery of receptors at the synapse highly attractive (for a cartoon on the type of protein complexes likely to be established by DLGS97 and DLGA, see supplemental Fig. S5, available at www.jneurosci.org as supplemental material).

Another feature DLGS97 proteins have is their ability to regulate the switch-like characteristics of MAGUKs. The GUK and SH3 domains of PSD95 and SAP97 can establish intramolecular interactions rendering the proteins in an open (available for partner binding) or closed configuration (McGee and Bredt, 1999;
Shin et al., 2000). Notably, the N-terminal extension of SAP97 can inhibit these intramolecular interactions (Wu et al., 2000). Thus, L27 domain-containing proteins have an additional level of regulation able to regulate MAGUK interactions with binding partners.

Remarkably, a recent report shows that the mammalian MAGUKs PSD95 and SAP97 are expressed in the CNS as alternative splice forms containing or lacking an L27 domain. Furthermore, these studies suggest that only the L27 domain-bearing forms are sensitive to activity associated to the CaMKII activity (Schluter et al., 2006), supporting a role of the L27 domain in activity-induced synaptic modification.

A significant finding in this work is the versatility of SAP proteins within the same cell. Although eliminating either of the two isoforms did not prevent normal localization of Scrib, FasII localization was altered in both $d \lg S 97$ and $d \lg A$ mutants, although the total amount of DLG was only decreased at most by $20 \%$. These observations are intriguing, given that FasII and Scrib interact with DLG domains present in both isoforms (Thomas et al., 1997; Mathew et al., 2002). This suggests that form-specific characteristics or the interaction or balance between the two proteins are important for proper FasII localization. Similar codependence/independence between isoforms was found at the ultrastructural level. Although both isoforms appeared to be required for the regulation of active zones, bouton and synaptic vesicle size, either of them had functions in SSR development. 
The detected abnormalities in synaptic architecture were also accompanied by functional alterations. The mEJP amplitude change of $d l g^{X I-2}$ was phenocopied when DLGS97 was eliminated, whereas the absence of DLGA did not increase the amplitude of the mEJPs. The increase of mEJPs amplitude was correlated with an increase in the size of the vesicles (significant for all genotypes) and an increase in the labeling intensity and size of the GluR clusters only in $d l g S 97$ mutants. Thus, the increased mEJP amplitude in $d \operatorname{lgS} 97$ mutants correlates with presynaptic and postsynaptic defects. However, the decrease in EJP amplitude depended only on DLGA. Overall, both mutants had a decrease in quantal content, indicating that both isoforms are required for effective neurotransmission. Such SAP-specific functions between PSD95 and SAP97 have been suggested in neuronal culture studies (Tiffany et al., 2000; Cai et al., 2006).

We found a striking shift in isoform usage during development, with DLGS97 becoming increasingly preponderant at more mature stages. These results, added to the previously described DLGS97 exclusive expression in excitable tissues, suggest that this shift underscores a fundamental and unique requirement of the L27 domain in neurons. A similar developmental shift is observed in mammalian neuronal cultures, in which PSD95 and PSD93 (proteins that bear L27 domains as splice variants) play most relevant roles in mature neurons, whereas SAP102 (lacking L27 domain) is essential in immature neurons (Elias et al., 2006). Thus, although SAPs devoid of L27 domain might have roles in protein clustering in a broad number of polarized cells, L27-bearing SAPs might couple the basic clustering machinery to multiple cellular processes. Our isolation of isoform-specific mutants in the absence of SAP redundancy constitutes the first step to address this possibility.

We highlight the correlation between the acquisition of a single domain of protein-protein interaction and the ability of DLGS97 to engage in processes required for complex functions of the adult brain. Although the mechanisms mediating between both levels need to be unraveled and are probably multiple, this example appears relevant to understand the elaboration of increasingly complex structures and functions with a limited set of molecular tools.

\section{References}

Anholt RR, Lyman RF, Mackay TF (1996) Effects of single P-element insertions on olfactory behavior in Drosophila melanogaster. Genetics 143:293-301.

Ashley J, Packard M, Ataman B, Budnik V (2005) Fasciclin II signals new synapse formation through amyloid precursor protein and the scaffolding protein dX11/Mint. J Neurosci 25:5943-5955.

Ataman B, Budnik V, Thomas U (2006) Scaffolding proteins at the Drosophila neuromuscular junction. Int Rev Neurobiol 75:181-216.

Bachmann A, Timmer M, Sierralta J, Pietrini G, Gundelfinger ED, Knust E, Thomas U (2004) Cell type-specific recruitment of Drosophila Lin-7 to distinct MAGUK-based protein complexes defines novel roles for Sdt and Dlg-S97. J Cell Sci 117:1899-1909.

Benzer S (1967) Behavioral mutants of Drosophila isolated by countercurrent distribution. Proc Natl Acad Sci USA 58:1112-1119.

Budnik V, Koh YH, Guan B, Hartmann B, Hough C, Woods D, Gorczyca M (1996) Regulation of synapse structure and function by the Drosophila tumor suppressor gene dlg. Neuron 17:627-640.

Cai C, Li H, Rivera C, Keinanen K (2006) Interaction between SAP97 and PSD-95, two Maguk proteins involved in synaptic trafficking of AMPA receptors. J Biol Chem 281:4267-4273.

Caruana G, Bernstein A (2001) Craniofacial dysmorphogenesis including cleft palate in mice with an insertional mutation in the discs large gene. Mol Cell Biol 21:1475-1483.

Chetkovich DM, Chen L, Stocker TJ, Nicoll RA, Bredt DS (2002) Phosphorylation of the postsynaptic density-95 (PSD-95)/discs large/zona occludens- 1 binding site of stargazin regulates binding to PSD-95 and synaptic targeting of AMPA receptors. J Neurosci 22:5791-5796.

Doerks T, Bork P, Kamberov E, Makarova O, Muecke S, Margolis B (2000) L27, a novel heterodimerization domain in receptor targeting proteins Lin-2 and Lin-7. Trends Biochem Sci 25:317-318.

Elias GM, Funke L, Stein V, Grant SG, Bredt DS, Nicoll RA (2006) Synapsespecific and developmentally regulated targeting of AMPA receptors by a family of MAGUK scaffolding proteins. Neuron 52:307-320.

Fanning AS, Anderson JM (1999) Protein modules as organizers of membrane structure. Curr Opin Cell Biol 11:432-439.

Feng W, Long JF, Fan JS, Suetake T, Zhang M (2004) The tetrameric L27 domain complex as an organization platform for supramolecular assemblies. Nat Struct Mol Biol 11:475-480.

Funke L, Dakoji S, Bredt DS (2005) Membrane-associated guanylate kinases regulate adhesion and plasticity at cell junctions. Annu Rev Biochem 74:219-245.

Gaines P, Tompkins L, Woodard CT, Carlson JR (2000) quick-to-court, a Drosophila mutant with elevated levels of sexual behavior, is defective in a predicted coiled-coil protein. Genetics 154:1627-1637.

Garner CC, Kindler S, Gundelfinger ED (2000a) Molecular determinants of presynaptic active zones. Curr Opin Neurobiol 10:321-327.

Garner CC, Nash J, Huganir RL (2000b) PDZ domains in synapse assembly and signalling. Trends Cell Biol 10:274-280.

Helfrich-Forster C (2003) The neuroarchitecture of the circadian clock in the brain of Drosophila melanogaster. Microsc Res Tech 62:94-102.

Karunanithi S, Marin L, Wong K, Atwood HL (2002) Quantal size and variation determined by vesicle size in normal and mutant Drosophila glutamatergic synapses. J Neurosci 22:10267-10276.

Kittel RJ, Hallermann S, Thomsen S, Wichmann C, Sigrist SJ, Heckmann M (2006) Active zone assembly and synaptic release. Biochem Soc Trans 34:939-941.

Klocker N, Bunn RC, Schnell E, Caruana G, Bernstein A, Nicoll RA, Bredt DS (2002) Synaptic glutamate receptor clustering in mice lacking the SH3 and GK domains of SAP97. Eur J Neurosci 16:1517-1522.

Lahey T, Gorczyca M, Jia XX, Budnik V (1994) The Drosophila tumor suppressor gene dlg is required for normal synaptic bouton structure. Neuron 13:823-835.

Lee S, Fan S, Makarova O, Straight S, Margolis B (2002) A novel and conserved protein-protein interaction domain of mammalian Lin-2/CASK binds and recruits SAP97 to the lateral surface of epithelia. Mol Cell Biol 22:1778-1791.

Lu CS, Hodge JJ, Mehren J, Sun XX, Griffith LC (2003) Regulation of the $\mathrm{Ca}^{2+} / \mathrm{CaM}$-responsive pool of CaMKII by scaffold-dependent autophosphorylation. Neuron 40:1185-1197.

Marfatia SM, Byron O, Campbell G, Liu SC, Chishti AH (2000) Human homologue of the Drosophila discs large tumor suppressor protein forms an oligomer in solution. Identification of the self-association site. J Biol Chem 275:13759-13770.

Marrus SB, Portman SL, Allen MJ, Moffat KG, DiAntonio A (2004) Differential localization of glutamate receptor subunits at the Drosophila neuromuscular junction. J Neurosci 24:1406-1415.

Martin JR, Ollo R (1996) A new Drosophila $\mathrm{Ca}^{2+} /$ calmodulin-dependent protein kinase (Caki) is localized in the central nervous system and implicated in walking speed. EMBO J 15:1865-1876.

Mathew D, Gramates LS, Packard M, Thomas U, Bilder D, Perrimon N, Gorczyca M, Budnik V (2002) Recruitment of scribble to the synaptic scaffolding complex requires GUK-holder, a novel DLG binding protein. Curr Biol 12:531-539.

Mauceri D, Cattabeni F, Di Luca M, Gardoni F (2004) Calcium/ calmodulin-dependent protein kinase II phosphorylation drives synapseassociated protein 97 into spines. J Biol Chem 279:23813-23821.

McGee AW, Bredt DS (1999) Identification of an intramolecular interaction between the SH3 and guanylate kinase domains of PSD-95. J Biol Chem 274:17431-17436.

McGee AW, Topinka JR, Hashimoto K, Petralia RS, Kakizawa S, Kauer FW, Aguilera-Moreno A, Wenthold RJ, Kano M, Bredt DS (2001) PSD-93 knock-out mice reveal that neuronal MAGUKs are not required for development or function of parallel fiber synapses in cerebellum. J Neurosci 21:3085-3091.

Mendoza C, Olguin P, Lafferte G, Thomas U, Ebitsch S, Gundelfinger ED, Kukuljan M, Sierralta J (2003) Novel isoforms of Dlg are fundamental 
for neuronal development in Drosophila. J Neurosci [Correction (2007) 27(11)] 23:2093-2101.

Migaud M, Charlesworth P, Dempster M, Webster LC, Watabe AM, Makhinson M, He Y, Ramsay MF, Morris RG, Morrison JH, O’Dell TJ, Grant SG (1998) Enhanced long-term potentiation and impaired learning in mice with mutant postsynaptic density-95 protein. Nature 396:433-439.

Nakagawa T, Futai K, Lashuel HA, Lo I, Okamoto K, Walz T, Hayashi Y, Sheng M (2004) Quaternary structure, protein dynamics, and synaptic function of SAP97 controlled by L27 domain interactions. Neuron 44:453-467.

Ohshiro T, Yagami T, Zhang C, Matsuzaki F (2000) Role of cortical tumoursuppressor proteins in asymmetric division of Drosophila neuroblast. Nature 408:593-596.

Pak WL (1979) Study of photoreceptor function using Drosophila mutants. In: Neurogenetics: genetic approaches to the nervous system (Breakfield XO, ed), pp 67-99. New York: Elsevier.

Parnas D, Haghighi AP, Fetter RD, Kim SW, Goodman CS (2001) Regulation of postsynaptic structure and protein localization by the Rho-type guanine nucleotide exchange factor dPix. Neuron 32:415-424.

Perrimon N (1988) The maternal effect of lethal(1)discs-large-1: a recessive oncogene of Drosophila melanogaster. Dev Biol 127:392-407.

Petrosky KY, Ou HD, Lohr F, Dotsch V, Lim WA (2005) A general model for preferential hetero-oligomerization of LIN-2/7 domains: mechanism underlying directed assembly of supramolecular signaling complexes. J Biol Chem 280:38528-38536.

Prokop A (2006) Organization of the efferent system and structure of neuromuscular junctions in Drosophila. Int Rev Neurobiol 75:71-90.

Regalado MP, Terry-Lorenzo RT, Waites CL, Garner CC, Malenka RC (2006) Transsynaptic signaling by postsynaptic synapse-associated protein 97. J Neurosci 26:2343-2357.

Rogero O, Hammerle B, Tejedor FJ (1997) Diverse expression and distribution of Shaker potassium channels during the development of the Drosophila nervous system. J Neurosci 17:5108-5118.

Ruiz-Canada C, Koh YH, Budnik V, Tejedor FJ (2002) DLG differentially localizes Shaker $\mathrm{K}^{+}$-channels in the central nervous system and retina of Drosophila. J Neurochem 82:1490-1501.

Rumbaugh G, Sia GM, Garner CC, Huganir RL (2003) Synapse-associated protein-97 isoform-specific regulation of surface AMPA receptors and synaptic function in cultured neurons. J Neurosci 23:4567-4576.

Schluter OM, Xu W, Malenka RC (2006) Alternative N-terminal domains of PSD-95 and SAP97 govern activity-dependent regulation of synaptic AMPA receptor function. Neuron 51:99-111.
Sheng M, Lee SH (2001) AMPA receptor trafficking and the control of synaptic transmission. Cell 105:825-828.

Shin H, Hsueh YP, Yang FC, Kim E, Sheng M (2000) An intramolecular interaction between Src homology 3 domain and guanylate kinase-like domain required for channel clustering by postsynaptic density-95/ SAP90. J Neurosci 20:3580-3587.

Tejedor FJ, Bokhari A, Rogero O, Gorczyca M, Zhang J, Kim E, Sheng M, Budnik V (1997) Essential role for dlg in synaptic clustering of Shaker $\mathrm{K}^{+}$channels in vivo. J Neurosci 17:152-159.

Tepass U, Tanentzapf G, Ward R, Fehon R (2001) Epithelial cell polarity and cell junctions in Drosophila. Annu Rev Genet 35:747-784.

Thomas U, Kim E, Kuhlendahl S, Koh YH, Gundelfinger ED, Sheng M, Garner CC, Budnik V (1997) Synaptic clustering of the cell adhesion molecule fasciclin II by discs-large and its role in the regulation of presynaptic structure. Neuron 19:787-799.

Tiffany AM, Manganas LN, Kim E, Hsueh YP, Sheng M, Trimmer JS (2000) PSD-95 and SAP97 exhibit distinct mechanisms for regulating $\mathrm{K}^{+}$channel surface expression and clustering. J Cell Biol 148:147-158.

Tsunoda S, Sierralta J, Sun Y, Bodner R, Suzuki E, Becker A, Socolich M, Zuker CS (1997) A multivalent PDZ-domain protein assembles signalling complexes in a G-protein-coupled cascade. Nature 388:243-249.

Wheeler DA, Hamblen-Coyle MJ, Dushay MS, Hall JC (1993) Behavior in light-dark cycles of Drosophila mutants that are arrhythmic, blind, or both. J Biol Rhythms 8:67-94.

Woods DF, Bryant PJ (1991) The discs-large tumor suppressor gene of Drosophila encodes a guanylate kinase homolog localized at septate junctions. Cell 66:451-464.

Woods DF, Hough C, Peel D, Callaini G, Bryant PJ (1996) Dlg protein is required for junction structure, cell polarity, and proliferation control in Drosophila epithelia. J Cell Biol 134:1469-1482.

Wu H, Reissner C, Kuhlendahl S, Coblentz B, Reuver S, Kindler S, Gundelfinger ED, Garner CC (2000) Intramolecular interactions regulate SAP97 binding to GKAP. EMBO J 19:5740-5751.

Wu H, Nash JE, Zamorano P, Garner CC (2002) Interaction of SAP97 with minus-end-directed actin motor myosin. VI. Implications for AMPA receptor trafficking. J Biol Chem 277:30928-30934.

Xu Y, Condell M, Plesken H, Edelman-Novemsky I, Ma J, Ren M, Schlame M (2006) A Drosophila model of Barth syndrome. Proc Natl Acad Sci USA 103:11584-11588.

Zordan MA, Massironi M, Ducato MG, Te Kronnie G, Costa R, Reggiani C, Chagneau C, Martin JR, Megighian A (2005) Drosophila CAKI/CMG protein, a homolog of human CASK, is essential for regulation of neurotransmitter vesicle release. J Neurophysiol 94:1074-1083. 